\title{
Does participatory forest management change household attitudes towards forest conservation and management?
}

\author{
Matiku Paul $^{1 \star}$, Mireri Caleb ${ }^{2}$ and Ogol Callistus ${ }^{2}$ \\ ${ }^{1}$ Nature Kenya, P. O. Box 44486, 00100, Nairobi, Kenya. \\ ${ }^{2}$ Kenyatta University, P. O. Box 43844, 00100, Nairobi, Kenya.
}

Accepted 19 March, 2012

\begin{abstract}
The study assessed the impact of participatory forest management (PFM) on household attitudes towards conservation and management of Arabuko-Sokoke Forest. The results obtained show that the impact of the forest on households was positive and higher in households in PFM zones than in those in non-PFM zones. There were higher proportions of households in PFM zones than in non-PFM zones, although it was a good objective to create the forest. They have good relations with the forest, benefit quite a deal from it as they obtain forest-related products from the forest; and want it protected. Also, the land adjacent to the forest has higher positive impact on household livelihood than the land further away. Higher proportions of households in non-PFM zones than PFM zones have poor relations with the forest as they are unhappy with the fact that the forest is linked to livestock deaths through tsetse fly, crop damage by wild animals, and predation of livestock without income generating activities to offset these losses. The study concluded that PFM is an asset for forest conservation in ArabukoSokoke Forest.
\end{abstract}

Key words: Participatory forest management, household, benefit, cost, Arabuko-Sokoke.

\section{INTRODUCTION}

In most parts of Africa, forest departments were set up to manage forest reserves in order to maintain colonial authorities' user rights to valuable timber, and in part to protect important watersheds, ecosystems, and habitats (McGregor, 1991a). The governments in eastern and southern Africa failed to evict people and this led to the realization that co-management approaches that involve greater role of local communities, the rural and urban poor as well as the private sector in the management of forests is the only solution (Barrow et al., 2002). In 1991, 96\% of households in Arabuko-Sokoke were unhappy with the Arabuko-Sokoke Forest, while 54\% wanted the forest completely cleared for settlement (Mogaka, 1991).

Co-management captures the idea that rights and responsibilities should be shared among those who lay

${ }^{\star}$ Corresponding author. E-mail: matiku@naturekenya.org. Tel: 254-20-714741849. claim to the environment or natural resources. Singleton (2002) observes that it would be difficult to find any recent environmental policy initiatives that do not contain prominent references to the need to move away from topdown directives towards consensus-based processes and community participation in planning, implementing, and monitoring new policies. The concept of comanagement has evolved with both research and experience (Plummer and Armitage, 2007c). Early definitions and representations focused on dualistic power-sharing between the state and local (or indigenous) resource users and the range of possible arrangements (Pinkerton, 1989; Berkes et al., 1991; Berkes, 1994). Subsequently, the spectrum of individuals potentially involved in co-management was broadened to include a wider array of actors, and co-management was advanced as a continuous problem-solving process (Plummer and FitzGibbon, 2004b; Carlsson and Berkes, 2005; Plummer, 2006). Recently, the dynamism inherent in the co-management process was highlighted in relation 
to knowledge generation, social learning, and adaptation for transformative changes (Berkes, 2009).

Although, it is important to recognize that adaptive comanagement is not a governance panacea, conditions that contribute to successful outcomes are beginning to emerge from practice. These include well-defined resource systems and small-scale contexts, shared interests by an identifiable set of social entities, clear property rights, access to adaptable management measures, commitment to a long-term process of institution building, availability of training and resources, presence of key leaders or champions, openness of participants to embrace plurality of knowledge, and a supportive policy environment (Armitage et al., 2009).

Previous studies focused on proposals for a range of natural resources management tactics such as providing appropriate development opportunities (Abbot et al., 2001), emphasizing local community involvement (Western, 1994; Getz et al., 1999), adopting shared management (Murphree, 1994), ensuring local autonomy (Muller, 2003), guaranteeing rights to harvest (Fearnside, 1989; Browder, 1992), promoting knowledge (Jacobson and McDuff, 1998), awarding direct cash compensation (Ferraro and Kiss, 2002), and encouraging tourism (Honey, 1999) without emphasizing the impact of the initiatives on the household income of forest-adjacent dwellers. Previous studies also focused on local community dependency on forests (Suda, 1992; Emerton, 1993), the demand for indigenous timber (Rheker, 1992), illegal timber felling (Emerton, 1995a, 1992; Marshall and Jenkins, 1994), and forest costs (Emerton, 1995a; Thomson and Ochieng, 1993; Thomson, 1993) that are usually targeted by participatory forest management initiatives.

The sustainable livelihood framework by Scoones (1998) predicts that if the right policy and institutional framework is put in place, if livelihood resources are identified and their use defined, and if local institutions have the right governance structures, then the use of such resources will adopt sustainable means that will guarantee sustainable livelihood outcomes. Scoones (1998) also defines sustainable livelihood outcomes as taking the form of: (i) improved well-being and capabilities resulting from reduced poverty due to increased household incomes and (ii) ensured livelihood sustainability which results in enhanced household livelihood adaptation, vulnerability and resilience due to natural resource base sustainability. Participatory Forest Management (PFM) is an arrangement where key stakeholders enter into mutually enforceable agreements that define their respective roles, responsibilities, governance, policy, institutional structures, benefits, and authority in the management of defined forest resources (Warah, 2008). The main objective of PFM is to ensure wider local ownership and support for forest conservation. The necessity of ensuring clear incentives for local communities to limit local community resource usage to sustainable levels, including the provision of non-forest alternative sources of income and subsistence and legitimate participation in forest management are considered as important components of sustainable natural resource management strategies in Kenya (Barrow, 1988; Emerton, 1995a, b, 1996a, b, c; Emerton and Mogaka, 1996).

Despite the prominence of strategies linking conservation and development as primary conservation tools and strong arguments for and against their effecttiveness (Wells et al., 1992; Barrett and Arcese, 1995; Oates, 1999; McShane and Wells, 2004), there have been few quantitative comparative assessments of their successes and failures. Nkhata et al. (2008) observe that notwithstanding a growing appreciation of the importance of collaboration, little attention has, evidently, been given to the dynamic long-term social relationships that underlie collaborative schemes in the management of natural resources. This void raises an important question: "Is collaborative natural resources management an asset or liability for natural resources conservation?"

The present study assessed the impact of PFM on the attitudes of households towards forest conservation and management in and around Arabuko-Sokoke Forest. The question answered in this study was: "Are the attitudes of households adjacent to PFM zones different from those of households from non-PFM zones around the ArabukoSokoke Forest?" The hypothesis tested in study was: "the attitudes of households adjacent to PFM zones are more positive to forest conservation than those of households from non-PFM zones in Arabuko-Sokoke Forest".

\section{MATERIALS AND METHODS}

\section{General methods}

The study used socio-economic research methods in forestry by Harrison et al. (2002) to collect data on the impact of PFM on household livelihood. Following the method of Harrison et al. (2002), the reference population for interview was selected from the heads of households in the study zones. The heads of households are the people who have the experience, knowledge, and skills to provide reliable information on the study variables. Questionnaires were developed to cover household wealth measures for households living up to $5 \mathrm{~km}$ equidistance from the edge of the forest. The questionnaires were administered using personal interview approach which was very good for avoiding non-response biases (Harrison et al., 2002). To validate the questionnaires, errors were eliminated first, and five enumerators were identified on the basis of their ability to understand and interpret the contents of the questionnaires, which were written in simple English language. The five enumerators were trained for two days. Each enumerator was given five test questionnaires to administer as a pilot. The questionnaires were then adjusted to ensure clarity on all the questions. The testing of the questionnaires also allowed a reasonable estimation of the time to be taken to administer one questionnaire. It was established that each questionnaire would require two hours.

On the field application of the questionnaires, data on forest benefits and losses were collected following the method of Dosman et al. (2002) who assessed the subsistence use of forest for 


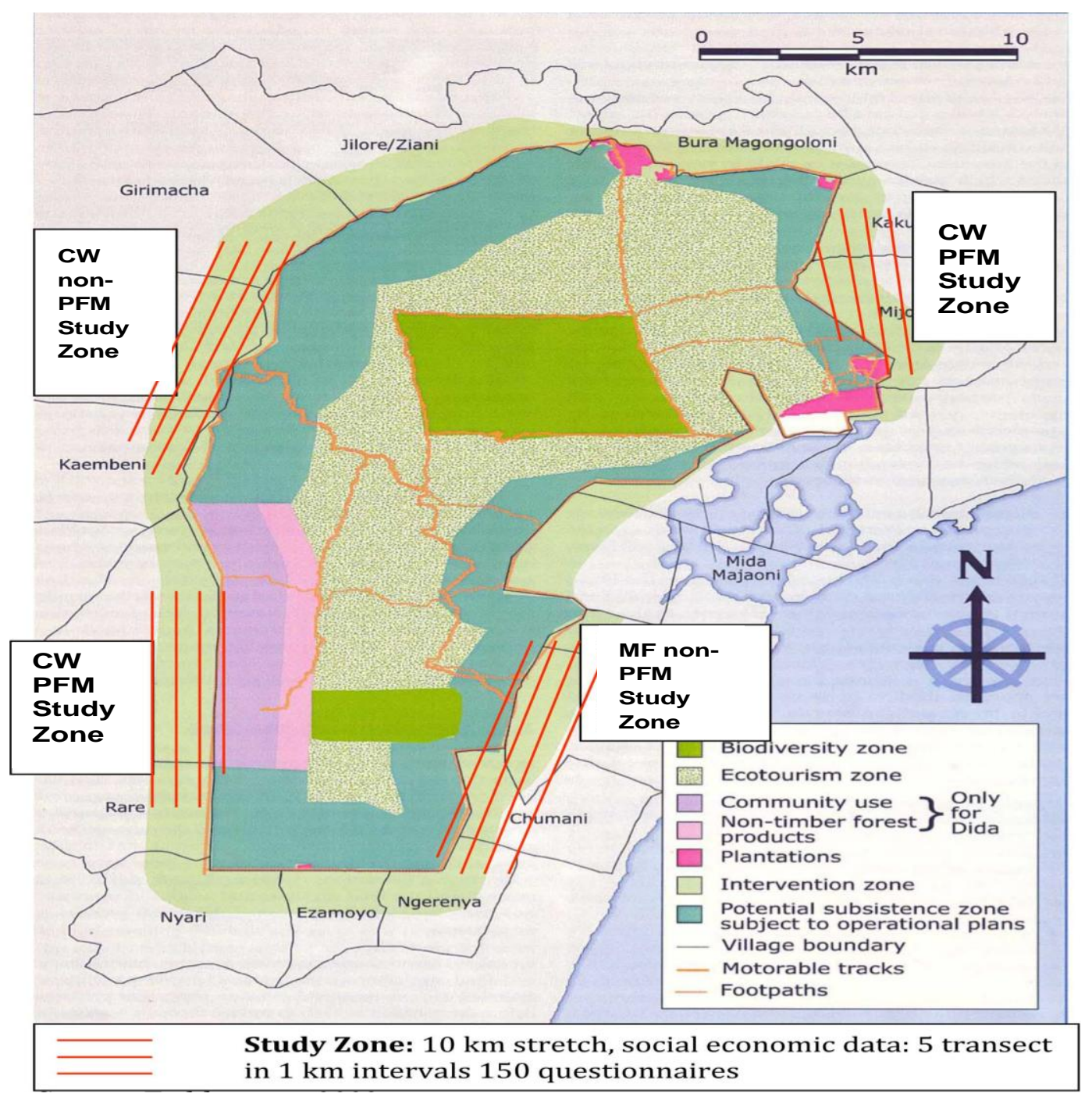

Figure 1. Map showing the data collection zones in the MF and CW of the PFM and non-PFM zones in Arabuko-Sokoke Forest.

aboriginal peoples. The study also used the method of Adamowicz et al. (2004) who assessed subsistence hunting of the Aboriginal people. It equally used the method of Emerton (1992) and Mogaka (1991a) who applied similar techniques to assess subsistence forest uses in Mountain Kenya and Aberdares Forests in Kenya. Data on the impact of PFM on household wealth were collected following the method of Barrett and Arcese, 1995, Brooks et al. (2006), McShane et al. (2004) and Morgan-brown et al. (2009). These used questionnaires and interview methods to assess the conservation efficacy of conservation and development initiatives in different parts of the world.

\section{The sampling frame}

Data were collected from 150 households in each of the PFM and non-PFM zones at 1, 2, 3, 4, and $5 \mathrm{~km}$ distances from the edge of the forest in both the Mixed Forest (MF) and Cynometra woodland (CW) of the PFM and non-PFM zones, leading to a total of 600 questionnaires (Figure 1). Each transect length was $10 \mathrm{~km}$ in each of the four study zones.
At the initial stage, the number of households in the study areas was listed and each household was given a number.

Households were categorised into each of the 1 to $5 \mathrm{~km}$ distances as mentioned earlier from the edge of the forest to capture differences in benefits and losses and household perceptions resulting from household distance differences from the edge of the forest over the $10 \mathrm{~km}$ transect length. At the next stage, random sampling was used to pick a sample of thirty households from each sampling distance, making a total of 150 randomly selected households for each of the MF and CW in the PFM and non-PFM study zones and resulting in a total of 600 households (Figure 1).

The enumerators visited the households walking from one household to the next within the sampled households. Each head of household was interviewed by a trained enumerator who verbally asked each of the questions in the questionnaire in series. The heads of households who could not understand English were asked in vernacular by the enumerator translating the questions verbally into vernacular. Answers were recorded by the enumerator against each of the questions. The heads of households were allowed to engage in discussions and story-telling to better understand the questions and provide answers. The data were collected between 
Table 1. Comparisons between Chi-square values of the positive and negative attitudes of households towards the forest and impact of forest on household livelihood.

\begin{tabular}{|c|c|c|c|c|}
\hline Parameter & Numbers of HH (A) & Parameter & Numbers of $\mathrm{HH}(\mathrm{B})$ & $\chi^{2}$ (A vs. B) \\
\hline ASF has +ve impact on livelihood & 475 & ASF has -ve impact on livelihood & 186 & $41760.5^{*}$ \\
\hline ASF has high +ve impact & 72 & ASF has medium +ve impact & 300 & $25992^{*}$ \\
\hline ASF has high +ve impact & 72 & ASF has low +ve impact & 103 & $480.5^{\star}$ \\
\hline ASF has medium +ve impact & 300 & ASF has low +ve impact & 103 & $19404.5^{\star}$ \\
\hline ASF has high -ve & 53 & ASF has medium -ve impact & 107 & $1458^{*}$ \\
\hline ASF has high -ve impact & 53 & ASF has low -ve impact & 26 & $374.5^{\star}$ \\
\hline ASF has medium -ve impact & 107 & ASF has low -ve impact & 26 & $3280.5^{\star}$ \\
\hline Higher impact: Land adjacent & 258 & Higher impact: Land further away & 181 & $2964.5^{\star}$ \\
\hline Higher impact: Land adjacent & 258 & No difference in impact & 17 & $29040.5^{\star}$ \\
\hline High impact: Land further away & 181 & No difference in impact & 17 & $13448^{*}$ \\
\hline It is a good thing to create the forest & 490 & It is a bad thing to create the forest & 7 & 1.17E+05* \\
\hline It is a good thing to create the forest & 490 & Do not know if good or bad to create the forest & 2 & $1.19 \mathrm{E}+05^{*}$ \\
\hline It is a bad thing to create the forest & 7 & Do not know if it is good or bad to create the forest & 2 & $12.5^{\star}$ \\
\hline Good relations with ASF & 270 & Moderate relations with ASF & 168 & $5202^{*}$ \\
\hline Good relations with ASF & 270 & Poor relations with ASF & 53 & $23544.5^{*}$ \\
\hline Moderate relations with ASF & 168 & Poor relations with ASF & 53 & $6612.5^{*}$ \\
\hline Get quite a deal of benefits from the forest & 252 & Do not get quite a deal of benefits from the forest & 228 & $288^{*}$ \\
\hline
\end{tabular}

${ }^{*}=$ Significant $\chi^{2} ; \mathrm{p}<0.05 ; \mathrm{df}=1$. HH: Household.

the years 2008 and 2009. Where the head of a household was found to be absent, the next household not included in the sample was chosen for interview.

\section{Data collection and variables}

Firstly, a referendum was carried out on all the 600 sampled households to determine the local communities' perceptions on forest protection, involvement in forest management, value of land adjacent to the forest compared to that far away from the forest, and the overall positive and negative impact of the forest on local people. An opinion vote of whether the forest should or should not be protected was also part of the interview and the referendum. The data were collected from the MF in the PFM and non-PFM zones as well as from the CW in the PFM and non-PFM zones to ensure that the diversity of local communities and habitat types in Arabuko-Sokoke Forest were captured. The data were analyzed at two levels: (1) overall household attitudes towards forest conservation regardless of PFM or non-PFM zones and (2) household attitudes disaggregated into PFM and non-PFM zones. The data were analyzed using simple percentages and Chi-square test, comparing the proportions of household frequencies within each of the test household attitude variables. The analysis was done for the overall household attitudes towards forest conservation and household attitudes disaggregated into PFM and non-PFM zones of the MF and CW sampling zones.

\section{RESULTS}

\section{Household attitudes towards forest and livelihood}

The results showed that out of the total of 600 households, at least $72 \%(n=475)$ rely on Arabuko-Sokoke Forest for their livelihood, whereas $28 \%(n=186)$ argued that Arabuko-
Sokoke Forest has negative impact on their livelihood. The analysis of Chi-square statistics revealed a significant value for the household groups that have positive attitudes towards the conservation of the forest and livelihood management and the groups with negative attitudes towards the conservation of the forest and livelihood management $\left(\chi^{2}=4.18 \mathrm{E}+04\right.$; $\mathrm{p}<0.05 ; \mathrm{df}=1)($ Table 1$)$. Again, $63 \%(\mathrm{n}=300)$ of the households thought that the impact of the forest was moderate on livelihood management, while $22 \%(n=103)$ thought that positive impact was low and $15 \%(N=72)$ argued that the impact of the forest was high on household livelihood management (Table 1).

With regard to the negative impact of the forest, $58 \%(n=107)$ of the households thought that the 
forest has moderate negative impact, while $28 \%(n=53)$ believed that the forest has high negative impact and $14 \%(n=26)$ thought that the forest has low negative impact on household livelihood. The proportions of households who thought that the forest has moderate negative impact on livelihood were significantly higher than those who thought that the forest has high negative impact and low positive impact on household livelihood $\left(X^{2}=1458 ; P<0.05 ; d f=1\right)$ and $\left(X^{2}=3280.5 ; P<0.05 ; d f=\right.$ 1) respectively. However, the proportions of households that believed that the forest has high negative impact on their livelihood were higher than those who thought that the forest has low negative impact on their livelihood $\left(X^{2}\right.$ $=364.5 ; \mathrm{P}<0.05 ; \mathrm{df}=1)($ Table 1$)$.

In relation to the impact of household distance from the forest on livelihood, $56 \%(n=258)$ of the households believed that land adjacent to the forest has higher impact on their livelihood than land further away, while $40 \%(n=181)$ of the households thought that land further away from the forest has higher impact on household livelihood than adjacent land and $4 \%(N=17)$ of the households thought that household distance from the forest makes no difference on household livelihood; the Chi-square values were significant in favour of households which argued that land adjacent to the forest has higher positive impact on household livelihood $\left(X^{2}=\right.$ 2964.5; $\mathrm{P}<0.05 ; \mathrm{df}=1$ ) $($ Table 1$)$.

The results showed that $99 \%(n=490)$ of the households thought that it was a good idea to create the forest, while only $1 \% \quad(n=7)$ completely thought the opposite; the Chi-square test was significant in this regard $\left(X^{2}=116644.5 ; P<0.05 ; d f=1\right)($ Table 1$)$. The number of households that had good relations with the forest was $55 \%(n=270)$, while the number of households that had medium relations with the forest was $34 \%(n=168)$ and the number of households that had poor relations with the forest was $11 \%(n=53)$. The frequencies of households that had good relations with the forest were higher than those of households that had medium relations and those of households that had poor relations with the forest; Chi-squares were significant $\left(X^{2}\right.$ $=5202 ; \mathrm{P}<0.05 ; \mathrm{df}=1)$ and $\left(\mathrm{X}^{2}=23544.5 ; \mathrm{P}<0.05 ; \mathrm{df}=\right.$ $1)$, respectively. On the whole, $52 \%(n=252)$ of the households said that they get quite a deal of benefits from the forest, while the remaining $48 \%(n=228)$ were dissatisfied with the forest. The Chi-square values were significant in favor of those who get quite a deal of benefits from the forest $\left(X^{2}=288 ; P<0.05 ; d f=1\right)($ Table 1).

\section{Household attitudes towards the impact of forest conservation}

The results showed that PFM zones have higher frequencies of households which perceive that the forest has positive impact on their livelihood, while non-PFM zones have higher frequencies of households which thought that the forest has negative impact on their livelihood. Households which thought that the forest has a high positive impact in their livelihood were higher in the MF of the PFM zone than in the MF of the non-PFM zone $\left(X^{2}=312.5 ; P<0.05 ; d f=1\right)$. More households in the MF of the non-PFM zone than in the MF of the PFM zone thought that the impact of the forest on their livelihood was either medium $\left(X^{2}=200 ; P<0.05 ; d f=1\right)$ or low $\left(X^{2}=\right.$ 392; $P<0.05 ; d f=1)$. The number of households which thought that the forest has negative impact on their livelihood was higher in the MF of the non-PFM zone than in the MF of the PFM zone $\left(X^{2}=612.5 ; P<0.05\right.$; $d f=$ 1). The Chi-square value for those households that regarded the level of negative impact as high was significant in favour of households in the MF of the nonPFM zone $\left(X^{2}=1012.5 ; P<0.05 ; d f=1\right)$ (Table 2).

The trends were similar in the $\mathrm{CW}$ forest where significant Chi-square values favoured the $\mathrm{CW}$ of the PFM zone, revealing that more households there thought that the forest has high positive and medium positive impact on their livelihood than the households in the CW of the non-PFM zone $\left(X^{2}=112.5 ; P<0.05 ; d f=1\right)$ and $\left(X^{2}\right.$ $=512 ; \mathrm{P}<0.05 ; \mathrm{df}=1)$, respectively. Again, more households in the CW of the non-PFM zone than in the CW PFM zone thought that the forest has a low positive impact on household livelihood $\left(X^{2}=40.5 ; P<0.05 ; \mathrm{df}=\right.$ 1). Similarly, the CW of the non-PFM zone has more households which thought that the forest has negative impact compared to the CW of the PFM zone $\left(X^{2}=72\right.$; $\mathrm{P}<0.05 ; \mathrm{df}=1$ ) (Table 2).

With regard to the relative distance of households from the forest, Chi-square values are significant in favor of more households in the MF of the PFM zone which think that situating household dwellings on land adjacent to the forest has higher impact on their livelihood than situating them further away $\left(X^{2}=3784.5 ; \quad P<0.05 ; \quad d f=1\right)$. Significant Chi-square values favour more households in the MF of the non-PFM zone who think that situating household dwellings on land further away from forest has higher impact on household livelihood than situating it adjacent to the forest $\left(X^{2}=3528 ; P<0.05 ; d f=1\right)(T a b l e$ 2). However, in the CW of the non-PFM zones significant Chi-square value favours more households which think that situating household dwellings on land adjacent to the forest has high impact on household livelihood than it does households in the CW of the PFM zones $\left(X^{2}=\right.$ 220.5; $P<0.05 ; d f=1)$. Also, more households in the $C W$ of the PFM zone than in the CW of the non-PFM zone wish their household dwellings were situated on land further away from the forest as this has higher impact on household livelihood than land adjacent to the forest (X2 $=12.5 ; \mathrm{P}<0.05 ; \mathrm{df}=1$ ) (Table 2).

\section{Household attitudes towards their involvement in forest management}

The study results showed significant Chi-square values 
Table 2. Comparison of Chi-square values for household attitudes towards forest's impact on livelihood.

\begin{tabular}{|c|c|c|c|c|c|c|}
\hline Parameter & $\begin{array}{c}\text { MF PFM Zone } \\
\text { (A) }\end{array}$ & $\begin{array}{c}\text { MF non-PFM Zone } \\
\text { (B) }\end{array}$ & $\begin{array}{c}X^{2} \\
A \text { vs B } \\
\end{array}$ & $\begin{array}{l}\text { CW PFM Zone } \\
\text { (C) }\end{array}$ & $\begin{array}{c}\text { CW non-PFM Zone } \\
\text { (D) }\end{array}$ & $\begin{array}{c}X^{2} \\
\text { C vs D }\end{array}$ \\
\hline High +ve forest impact & 33 & 8 & $312.5^{*}$ & 23 & 8 & $112.5^{*}$ \\
\hline Medium +ve forest impact & 55 & 75 & $200^{*}$ & 69 & 101 & $512^{*}$ \\
\hline Low +ve forest impact & 24 & 52 & $392^{*}$ & 9 & 18 & $40.5^{\star}$ \\
\hline Mean +ve forest impact & 37 & 45 & $32^{*}$ & 34 & 42 & $32^{*}$ \\
\hline High -ve forest impact & 1 & 46 & $1012.5^{\star}$ & 4 & 3 & 0.5 \\
\hline Medium -ve forest impact & 3 & 57 & $1458^{*}$ & 10 & 37 & $364.5^{*}$ \\
\hline Low -ve forest impact & 4 & 11 & $24.5^{\star}$ & 1 & 10 & $40.5^{\star}$ \\
\hline Mean -ve forest impact & 3 & 38 & $612.5^{\star}$ & 5 & 17 & $72^{*}$ \\
\hline Higher value to dwellings on land adjacent to forest & 97 & 10 & $3784.5^{\star}$ & 65 & 86 & $220.5^{*}$ \\
\hline Higher value to dwellings on land further away & 27 & 111 & $3528^{*}$ & 24 & 19 & $12.5^{\star}$ \\
\hline
\end{tabular}

* = Significant $X^{2} ; p=0.05 ; d f=1 ;(A),(B),(C),(D)=$ Number of households.

were in favor of households in the MF of the PFM zone, which thought that it was a good thing to create the forest $\left(X^{2}=162 ; P<0.05 ; d f=1\right)$. Significant Chi-square values favored more households in the CW of the non-PFM zone, which thought that it was a good idea to create the forest $\left(X^{2}=648 ; P<0.05 ; \mathrm{df}=1\right)$ (Table 3). The MF of the PFM zone showed a higher number of households which has good relations with the forest $\left(X^{2}=1404.5 ; P<0.05, d f=1\right)$. Chi-square values are in favor of more households in the MF of the non-PFM zone, which had poor relations with the forest $\left(X^{2}=24.5 ; P<0.05 ; d f=1\right)$ and those who thought they got quite a deal of benefits from the forest $\left(X^{2}=242 ; P<0.05 ; d f=1\right)$.

Higher proportions of households in the $\mathrm{CW}$ of the PFM zone than in the CW of the non-PFM zone have good relations with the forest $\left(X^{2}=\right.$ 544.5; $\mathrm{P}<0.05 ; \mathrm{df}=1$ ). Unlike the $\mathrm{MF}$, the households which think they get quite a deal of benefits from the forest are more in number in the $\mathrm{CW}$ of the PFM zone than in the CW of the nonPFM zone $\left(X^{2}=648 ; P<0.05 ; d f=1\right)$. Significant
Chi-square values indicate that more households in the CW of the non-PFM zone than in the CW of the PFM zone are unhappy with the forest $\left(\mathrm{X}^{2}=\right.$ 2888; $P<0.05 ; d f=1$ ) (Table 3).

The study results showed that higher proportions of households in the MF of the PFM zone than in the MF of the non-PFM zone thought that they are adequately involved in forest management $\left(X^{2}=2450 ; \quad P<0.05 ; \quad d f=1\right)$. Conversely, higher proportions of households in the MF of the non-PFM zone than the MF PFM zone thought that they are not adequately involved in forest management $\left(X^{2}=1104.5\right.$; $\mathrm{P}<0.05 ; \mathrm{df}=1$ ).

A higher number of households in the MF of the PFM zone than in the MF of the non-PFM zone thought that the forest is well protected $\left(\mathrm{X}^{2}=\right.$ 5512.5; $P<0.05 ; \mathrm{df}=1$ ) and wanted the forest protected $\left(X^{2}=338 ; P<0.05 ; d f=1\right)$. Similarly, Chi-square values were more in favor of households in the CW of the PFM zone than in the CW of the non-PFM zone, which thought they are adequately involved in forest management
$\left(X^{2}=112.5 ; P<0.05 ; d f=1\right)$. Conversely, higher proportions of households in the CW of the nonPFM zone than in the CW of the PFM zone were not involved in forest management $\left(X^{2}=1512.5\right.$; $\mathrm{P}<0.05 ; \mathrm{df}=1$ ). However, significant Chi-square values were in favor of more households in the $\mathrm{CW}$ of the non-PFM zone than in the CW of the PFM zone, which thought that the forest is well protected $\left(X^{2}=2048 ; P<0.05 ; \mathrm{df}=1\right)$ and wanted the forest protected $\left(X^{2}=760.5 ; P<0.05 ; d f=1\right)$ (Table 3).

\section{DISCUSSION}

\section{Household attitudes towards the forest and forest impact on household livelihood}

It may be deduced that households which have poor relations with the forest are unhappy with the forest as it is associated with losses in the form of livestock deaths due to tsetse fly, crop damage by wild animals, especially elephants, and predation 


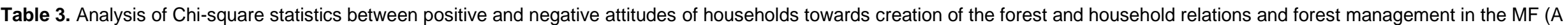
and $B)$ and $C W(C$ and $D)$ of the PFM and non-PFM zones.

\begin{tabular}{|c|c|c|c|c|c|c|}
\hline Parameter & $\begin{array}{c}\text { MF PFM Zones } \\
\text { (A) }\end{array}$ & $\begin{array}{c}\text { MF non-PFM Zone } \\
\text { (B) }\end{array}$ & $\begin{array}{c}X^{2} \\
\text { A vs B }\end{array}$ & $\begin{array}{l}\text { CW PFM Zone } \\
\text { (C) }\end{array}$ & $\begin{array}{l}\text { CW non-PFM } \\
\text { Zone (D) }\end{array}$ & $\begin{array}{c}\mathrm{X}^{2} \\
\mathrm{C} \text { vs D }\end{array}$ \\
\hline Good thing to create forest & 129 & 111 & $162^{*}$ & 107 & 143 & $648^{*}$ \\
\hline Good relations with forest & 92 & 39 & $1404.5^{\star}$ & 86 & 53 & $544.5^{*}$ \\
\hline Moderate relations with forest & 37 & 30 & $24.5^{\star}$ & 12 & 89 & $2964.5^{\star}$ \\
\hline Poor relations with forest & 1 & 40 & $760.5^{\star}$ & 11 & 1 & $50^{*}$ \\
\hline Forest is an asset to livelihood & 71 & 93 & $242^{*}$ & 62 & 26 & $648^{*}$ \\
\hline Forest is not an asset to livelihood & 59 & 13 & $1058^{*}$ & 40 & 116 & $2888^{*}$ \\
\hline Adequately involved in forest management & 71 & 1 & $2450^{*}$ & 48 & 33 & $112.5^{*}$ \\
\hline Not adequately involved forest management & 57 & 104 & $1104.5^{*}$ & 57 & 112 & $1512.5^{\star}$ \\
\hline Yes, forest is well protected & 108 & 3 & $5512.5^{\star}$ & 55 & 119 & $2048^{*}$ \\
\hline Forest is not well protected & 23 & 103 & $3200^{*}$ & 55 & 18 & $684.5^{\star}$ \\
\hline Yes, protect the forest & 130 & 104 & $338^{*}$ & 104 & 143 & $760.5^{\star}$ \\
\hline No, destroy the forest & 1 & 0 & 0.5 & 0 & 0 & 0 \\
\hline
\end{tabular}

* $=$ Significant $X^{2} ; p<0.05 ; d f=1 ;(A),(B),(C),(D)=$ Number of households

of livestock like chicken. The households who think they get quite a deal of benefits from the forest are expected to engage in genuine forest conservation, while those who do not support forest conservation could pose a major threat to the Arabuko-Sokoke Forest.

The results of the study show that household attitudes have changed since pre-PFM initiatives in 1991 when Mogaka (1991) found that $96 \%$ of the dwellers adjacent to the forest were unhappy with the forest, and 54\% wanted the forest completely cleared for settlement. The study of Mogaka (1991) was done at a time when there were no conservation and development initiatives with any conservation-based-income-generating activities. Therefore, the difference between the findings of this study and that of Mogaka (1991) could be strongly attributable to change of community attitudes influenced by incentives arising from a diversity of forest conservation tactics, especially income-generating activities, community education, awareness, and capacity building for PFM. Though, the results showed that the non-PFM zones are a liability, while the PFM zones are an asset, households in the non-PFM zones want the forest protected nevertheless, clearly indicating that the dwellers adjacent to forest want the forest protected whether or not the net effect of the forest on their livelihood is positive. This observation may indicate that the local households may not be aware of the costsbenefits equilibrium. As a result, households display skewed attitudes towards the forest benefits which they consider to have irreplaceable values. The households in the non-PFM zones may also be supporting forest conservation in anticipation of the incentives provided in the PFM zones. However, the findings of the study showed that the fact that some $48 \%$ of the households adjacent to the forest think that the forest benefits are not enough to offset the costs (that is, they do not get quite a deal of benefits from the forest) does present a worry for the forest conservation managers as they would be expected to continue engaging in unsustainable forest extraction.

\section{Household attitudes towards the impact of forest conservation}

The PFM zones were characterised by households who extract butterflies for export, harvest honey from bees in the forest, and engage in mushroom farming and eco-tourism initiatives. This may be the single most important reason why households in the PFM zones perceive the forest as an asset to livelihood and 
why they want the forest protected. The results agree with those of Alvard (1998) and Robinson et al. (2000) who noted that sustainable harvesting of some forest species can be a viable strategy in natural resources management. As PFM not only builds capacity, but promotes the sustainable use of some biodiversity components for example bees for honey, butterflies, and mushrooms there is no reason why such households should not support and engage in forest management consistent with the sustainable livelihood framework developed by Scoones (1998). This explains why higher proportions of households in PFM than non-PFM zones think that land adjacent to the forest has higher positive impact on household livelihood.

The fact that households in the PFM zones value their closeness to the forest due to the benefits that come from PFM investment in the form of livelihoods improvement agrees with the findings of Brooks (2006). The results further support the sustainable livelihood framework developed by Scoones (1998), which perceives sustainability from a multi-dimensional perspective. According to Scoones (1998), sustainable livelihood results from policy and institutional frameworks that support livelihood strategies and guarantee livelihood improvement and sustainability of the natural capital. This is in line with the PFM objectives in Arabuko-Sokoke Forest.

These results also agree with a range of other past studies, including Borgerhoff et al (2005) who recommended that conservation initiatives should address the welfare and cooperation of the people living in and around protected areas; Abbot et al. (2001) who said that such strategies should provide a mix of conservation and development objectives; and Western (1994) and Getz et al. (1999) who recommended employing a range of tactics such as providing appropriate development opportunities. The studies conducted by Murphree (1994) called for local community involvement which adopts shared management; Fearnside (1989) and Browder (1992) indicated that local people should be guaranteed the rights to harvest; Ferraro and Kiss (2002) recommended awarding cash compensation to offset conservation costs; and Honey (1999) encouraged tourism for livelihood improvement. In Arabuko-Sokoke Forest, the PFM process is a means of compensating for forest conservation costs through improving livelihood for forest conservation. While the results of the study agreed with past literature and though households supported forest conservation because of the benefits they received, the scale of benefit would be of significance if Arabuko-Sokoke Forest competed with other land uses.

\section{Household attitudes towards forest management}

The study results show that households in the MF of the
PFM zone, but not the CW of the PFM zone support the creation of Arabuko-Sokoke Forest. The results from the MF of the PFM zone agree with that of Ferraro and Kiss, (2002) who recommended awarding cash compensation to offset conservation costs and with that of Honey (1999) who encouraged tourism for livelihood improvement as a means to engage local people in forest conservation. It may be argued that due to the lack of forest protection enforcement usually associated with PFM, in the CW of the non-PFM zone, households have not been denied access to the forest and so they perceive the forest as a free resource that supplements their livelihood.

It may be argued that because of awareness creation associated with PFM investment, households in the CW of the PFM zone are aware that the forest resources are limited and the losses arising from the forest should be offset by nature-based enterprises. Since PFM resources are limited, until the time PFM resources become available in right scales, the households in the $\mathrm{CW}$ of the PFM zone would continue to view the forest as a liability to their livelihood since their welfare has not been addressed. Borgerhoff and Coppolillo (2005) recommended that conservation initiatives should address the welfare and cooperation of the people living in and around protected areas, while Abbot et al. (2001), Western (1994), and Getz et al. (1999) called for a mix of conservation and development objectives.

Murphree (1994) calls for local community involvement adopting shared management and Fearnside (1989) and Browder (1992) indicate that local people should be guaranteed the rights to harvest. The costs of forest conservation should be offset in the lines proposed by Ferraro and Kiss (2002) who recommend awarding cash compensation to offset conservation costs and Honey (1999) who encourages tourism for livelihoods improvement. In this study, results in the MF PFM zone where there has been significant PFM investment showed that PFM is a true asset to household livelihoods and is a tactic for improving the household attitudes towards forest conservation.

The results of this study agree with that of Brooks et al. (2006) who found that more community input in implementation is, indeed, linked with behavioural success, and that greater involvement in decision-making is associated with both behavioural success and ecological success. The study supports the claims of communitybased conservationists (Western and Wright, 1994) and allied approaches of Morgan-Brown et al. (2009) who studied butterfly farming in East Usambaras in Tanzania. They found that more than $80 \%$ of butterfly farmers believe forests are important for butterfly farming and that common illegal resource extraction activities pose a threat to wild butterflies. Furthermore, they found that more than $80 \%$ of butterfly farmers believed resource extraction activities such as pole cutting and logging were dangerous for wild butterfly populations, and that butterfly farming would be very difficult if forests were cleared. 
It is imperative that the results of the study support the view of Morgan-Brown et al. (2009) that butterfly farmers, beekeepers and mushroom farmers in Arabuko-Sokoke Forest do fear that clearance of Arabuko-Sokoke Forest will make them lose their livelihood. While there is undeniable evidence that many natural resources cannot withstand utilization (Alvard, 1998; Robinson and Bennett, 2000), sustainable harvesting of some species, as in the case of Arabuko-Sokoke Forest, can be a viable strategy in some cases where institutions regulating sustainable management are strong or when population sources remain protected (Hill et al., 1997).

Form the foregoing, it was deduced that that PFM investment is an asset to household livelihood and is a tactic for improving the household attitudes towards forest conservation. Community input in PFM implementation and extraction of forest products and capacity building is, indeed, linked with behavioural success leading to change of household attitudes necessary for their support towards forest conservation objecttives. The study also concludes that PFM investment should be high enough to deliver tangible benefits to participating dwellers adjacent to the forest, if they are to support forest conservation objectives.

\section{REFERENCES}

Abbot JIO, Thomas DHL, Gardner AA, Neba SE, Khen MW (2001). Understanding the links between conservation and development in the Bamenda highlands, Cameroon. World Dev., 29: 1115-1136.

Adamowicz W, Oxall P, Haener M, Zhang Y, Dosman D, Marois J (2004). An assessment of the impacts of forest management on Aboriginal hunters: Evidence from Stated and Revealed Preference Data. Forest Sci., 50(2): 141.

Armitage DR, Plummer R, Berkes F, Arthur RI, Charles AT, DavidsonHunt IJ, Diduck AP, Doubleday N, Johnson DS, Marschke M, McConney P, Pinkerton E, Wollenberg E (2009). Adaptive comanagement for social-ecological complexity. Frontiers Ecol. Environ., 6: 95-102.

Barrett CB, Arcese P (1995). Are integrated conservation-development projects (ICDPS) sustainable - on the conservation of large mammals in Sub-Saharan Africa. World Dev., 23:1073-1084.

Barrow E (1988). 'Trees and pastoralists: the case of the Pokot and the Turkana', Social Forestry Network Paper 6b, Overseas Development Institute, London.

Barrow E, Clarke J, Grundy I, Kamugisha Jones R, Tessema Y (2002). An analysis of stakeholders in community involvement in forest management in Eastern and Southern Africa, Nairobi, IUCN - EARO.

Berkes $F$ (1994). Co-management: bridging the two solitudes. Northern Perspect., 22: 18-20.

Berkes $F$ (2009). Evolution of co-management: role of knowledge generation, bridging organizations and social learning. J. Environ. Manage., 90: 1692-1702.

Berkes F, George PJ, Preston RJ (1991). The evolution of theory and practice of the joint administration of living resources. Alternative, 18 (2):12-18.

Brooks JS, Franzen MA, Holmes CM, Grote MN, Mulder MB (2006). Testing hypotheses for the success of different conservation strategies. Conserv. Biol., 20: 1528-1538.

Browder JO (1992). The limits of extractivism - tropical forest strategies beyond extractive reserves. Biosci., 42: 174-183.

Carlsson L, Berkes F (2005). Co-management: concepts and methodological implications. J. Environ. Manage., 75: 65-76.

Dosman D, Haener M, Adamowicz W, Marois J, Boxall P (2002).
Assessing impacts of environmental change on Aboriginal people: An economic examination of subsistence resource use and value. Department of Rural Economy, Faculty of Agriculture and Forestry, and Home Economics, University of Alberta, Edmonton, Canada.

Emerton L (1992). The Role of Indigenous Forests in the Kenyan National Economy, Forest Department, Nairobi.

Emerton L (1993). The Value of Kenya's indigenous forests to adjacent households, Forest Department, Nairobi.

Emerton L (1995a). Socio-economic notes on Mount Kenya Forest Reserve, Center for Biodiversity, National Museums of Kenya, Nairobi.

Emerton L (1995b). Socio-economic notes on Namanga Hill Forest Reserve, Center for Biodiversity, National Museums of Kenya, Nairobi.

Emerton L (1996a). Local economics and forest biodiversity loss', Paper presented at IUCN workshop on Economics and Biodiversity Loss, Geneva and Gland.

Emerton L (1996b). Maasai livelihoods, forest use and conservation in Oldonyo Orok, Kenya, Applied Conservation Economics Discussion Paper No. 2, African Wildlife Foundation, Nairobi.

Emerton L (1996c). 'Valuing the subsistence use of forest products in Oldonyo Orok forest, Kenya', Rural Development Forestry Network Paper 19e: 21-30, Overseas Development Institute, London.

Emerton L, Mogaka H (1996). Participatory environmental valuation: subsistence forest use around the Aberdares, Kenya', Participatory Learning and Action Notes. 26: 6-10, International Institute for Environment and Development, London; also published as Applied Conservation Economics Discussion Paper No. 1, African Wildlife Foundation, Nairobi.

Fearnside PM (1989). Extractive reserves in Brazilian Amazonia. Biosci., 39: 387-393.

Ferraro PJ, Kiss A (2002). Ecology - direct payments to conserve biodiversity. Science, 298: 1718-1719.

Getz WM, Fortmann L, Cumming D, du Toit J, Hilty J, Martin, R, Murphree M, Owen-Smith N, Starfield AM, Westphal MI (1999). Conservation - sustaining natural and human capital: villagers and scientists. Science, 283: 1855-1856.

Harrison S, Herbohn J, Mangaoang E, Vanclay J (2002). Socioeconomic Research Methods in Forestry: A training manual. Cooperative Research Centre for Tropical Rainforest Ecology and Management. Rainforest CRC, Cairns.

Jacobson SK, McDuff MD (1998). Conservation education. in W. J. Sutherland, editor. Conservation science and action. Blackwell Science, Oxford, pp. 237-255.

Marshall N, Jenkins M (1994). Hard times for hardwood: Indigenous timber and the timber trade in Kenya, TRAFFIC, Nairobi.

McGregor J (1991a). Woodland resources: ecology, policy and ideology. A historical case study of woodland use in Shurugwi communal area, Zimbabwe. Ph.D. thesis, Loughborough University of Technology, Loughborough.

McShane TO, Wells MP (2004). Getting biodiversity projects to work: Towards a more effective conservation and development. Columbia University Press, New York.

Mogaka H (1991a). Local utilization of Arabuko Sokoke Forest Reserve, IFCON/Forest Department, Ministry of Environment and Natural Resources, Nairobi.

Morgan-Brown T, Susan K, Kenneth W,Brian C (2009). Quantitative assessment of a tanzanian integrated conservation and development project involving butterfly farming. Conserv. Biol., 24, (2): 563-572.

Muller S (2003). Toward decolonisation of Australia's protected area management: the Nantawarrina Indigenous Protected Area experience. Australian Geog. Stud., 41: 29-43.

Murphree M (1994). The role of institutions in community-based conservation. pp. 403-427 in D. Western, and R. M. Wright, editors. Natural connections: perspectives on community-based conservation. Island Press, Washington, DC. Nkhata AB, Breen CM, Freimund WA (2008). Resilient social relationships and collaboration in the management of social-ecological systems. Ecol. Soc., 13(1): 2.

Oates JF (1999). Myth and reality in the rain forest: how conservation strategies are failing in West Africa. University of California Press, Berkeley. 
Pinkerton E (1989). Attaining better fisheries management through comanagement prospects, problems and propositions. pp. 3-33 in E. Pinkerton, editor. Co-operative management of local fisheries: new direction in improved management and community development. University of British Columbia Press, Vancouver, British Columbia, Canada.

Plummer R (2006). Sharing the management of a river corridor: a case study of the co-management process. Soc. Nat. Resour., 19:1-13.

Plummer R Armitage DR (2007b). Charting the new territory of adaptive comanagement: a Delphi study. Ecol. Soc., 12(2): 10.

Plummer R, FitzGibbon JE (2004b). Some observations on the terminology in co-operative environmental management. J. Environ. Manage., 70: 63-72.

Rheker J (1992). Forest management and timber industry at mount Kenya, Laikipia Research Program, Nanyuki and University Of Berne.

Scoones I (1998). Sustainable rural livelihoods: a framework for analysis. Working paper, vol. 72. Institute of Development Studies (IDS), Brighton, UK.

Singleton S (2002). Collaborative environmental planning in the American West: the good, the bad and the ugly. Environ. Politics $11: 3$.
Suda C (1992). Literature review on the use of indigenous forests in Kenya, Kenya Indigenous Forest Conservation Project/Institute of African Studies, University of Nairobi, Nairobi.

Thomson M, Ochieng D (1993). Field investigation of certain aspects of forest utilization in the Shimba Hills National Reserve and the Maluganji and Mkongani Forest Reserves, KIFCON/Forest Department, Ministry of Environment and Natural Resources, Nairobi.

Western D (1994). Ecosystem conservation and rural development: the case of Amboseli in D. Western, R. M. Wright, and S. C. Strum, editors. Natural connections: perspectives in community-based conservation. Island Press, Washington, DC.

Western D, Wright RM eds (1994). Natural connections: Perspectives in community based conservation. Washington, DC: Island Press. 